\title{
Primary calcified hydatid cyst of the brain
}

\author{
Devendra K Tyagi, Srikant Balasubramaniam, Hemant V Sawant \\ Department of Neurosurgery, T.N. Medical College and BYL Nair Hospital, Mumbai - 400 008, India
}

ABSTRACT

Cerebral hydatid disease is very rare, and in non-endemic areas like India, the occurrence is as low as $0.2 \%$ of all intracranial space occupying lesions. Calcification of the cyst wall indicates an even rarer subvariety, i.e., alveolar echinococcosis (AE). AE has hitherto been unreported in the Indian subcontinent. We report such a case in a 25 -yearold male, a shepherd by occupation, who presented to us with intractable seizures and headache. He had no gross lesion in the liver. Craniotomy with total excision of the lesion was performed, followed by antiparasitic treatment. The radiological presentation, differential diagnosis and treatment modalities are discussed in relation to our case.

Key words: Alveolar echinococcosis, calcified cyst wall, primary hydatid cyst

DOI: 10.4103/0976-3147.71729

\section{Introduction}

Cerebral hydatid disease is very rare, representing only $2 \%$ of all cerebral space occupying lesions even in the countries where the disease is endemic. ${ }^{[1]}$ Hydatid disease (echinococcosis) is a worldwide zoonosis produced by the larval stage of the Echinococcus tapeworm. In humans, the two main types of hydatid disease are caused by Echinococcus granulosus and Echinococcus multilocularis. ${ }^{[2,3]}$ Calcification is very rare but seen more commonly in infestation with E. multilocularis.

Various series of intracranial hydatids from India have reported its incidence as $0.2 \%$ of all intracranial space occupying lesions. In the Indian subcontinent, it is more commonly seen in the Kurnool district of Andhra Pradesh, Madurai district of Tamil Nadu and in Punjab. ${ }^{[4]}$

\section{Case Report}

We are presenting a case of an unexpectedly encountered intracranial hydatid cyst in a 25-year-old male. This gentleman, hailing from a remote village in Maharashtra, was a shepherd by occupation with history of contact with street dogs. He presented to us with seizures since 10 years and was on treatment from a local practitioner. A month prior to presentation to us, he had severe headache and occasional vomiting which might have been due to increase in cystic component of the lesion.
On examination, he had right-sided homonymous hemianopia, but no other deficit.

Computed tomography (CT) brain showed multiple serpentine, calcified, intensely enhancing, high attenuation lesions in the right occipital region, reported as calcified arteriovenous malformation (AVM) [Figure 1]. Magnetic resonance imaging (MRI) showed a focal lesion in the right occipital region which was hypo to isointense on T1W and hypo with peripheral hyperintensity on $\mathrm{T} 2 \mathrm{~W}$ images. The lesion was seen extending up to the occipital horn of the right lateral ventricle with ex-vacuo

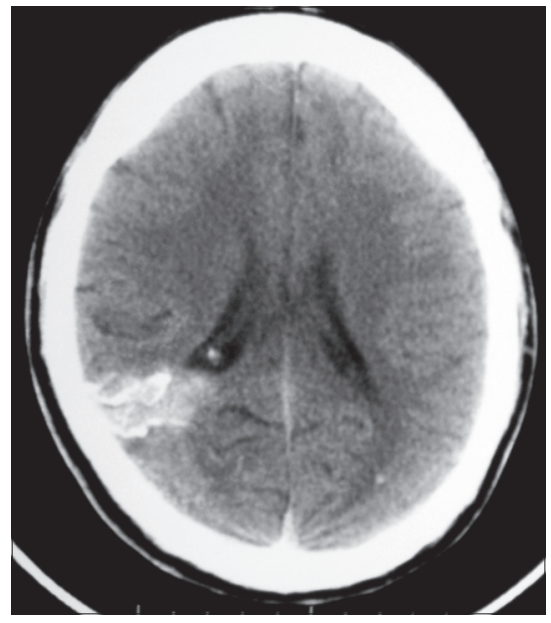

Figure 1: Plain axial CT scan showing a calcified lesion in the right occipital region, extending from the cortical surface till the ependyma of the lateral ventricle. There is also evidence of a small calcified granuloma in the left occipital lobe

\section{Address for correspondence:}

Dr. Srikant Balasubramaniam, Department of Neurosurgery, BYL Nair Hospital, Dr. A.L Nair Road, Mumbai Central, Mumbai - 400008 , India. E-mail: srikantbala@yahoo.com 
dilatation of the ventricle. Punctate blooming area was noted on gradient images, suggestive of calcification [Figure 2]. X-ray chest did not show any lesion in lungs. USG abdomen was also normal.

A right parieto-occipital craniotomy was performed and the dura was opened to visualize the lesion. The superficial surface of cyst was adherent to dura and the deeper surface to the ependyma of occipital horn of lateral ventricle. As we had not considered hydatid cyst as a differential diagnosis, we opened the cyst and the contents were sucked. However, there was no spillover of cyst contents. The contents were liquid with crystal/whitish flakes. The thick, calcified wall had a good plane of differentiation from the surrounding brain parenchyma [Figure 3]. It was excised in toto with gentle dissection. ntra op frozen was suggestive of a parasitic cyst. The cavity was then irrigated well with chloromycetin solution and hypertonic saline. There were no postoperative deficits and he showed good recovery from headache and improvement in homonymous hemianopia. As per our departmental protocol, he was given Tab. Albendazole $400 \mathrm{mg}$ twice a day for 1 month. Postoperative MRI showed complete excision of lesion, with no fresh lesions [Figure 4].

Histology revealed a cyst surrounded by gliotic brain parenchyma and host tissue reaction showing fibrocollagenous tissue lined by inflammatory cells and few giant cells. There were multiple calcific deposits, and remnants of hydatid cyst with characteristic laminated structures focally lined by germinal layer were also seen. Microscopy also revealed scolises with hooklets. Histological impression was suggestive of alveolar echinococcosis (AE). Hydatid serology was performed later, which turned out to be negative.

\section{Discussion}

Hydatid disease is endemic in the Middle East, Mediterranean countries, South America, North Africa and Australia. ${ }^{[5]}$ The liver (50-77\%) and the lung (8.5$43 \%$ ) are the organs most commonly involved. ${ }^{[2]}$ Cerebral hydatid disease is rare ( $2 \%$ of all hydatid infestations) and more common in pediatric population. ${ }^{[1,4]}$ Most of the cerebral hydatid cysts are supratentorial, usually located in the middle cerebral artery territory. The parietal lobe is the most frequently involved region. ${ }^{[6]}$

Two species of the genus Echinococcus are the most clinically relevant forms: the cystic echinococcosis (hydatid cyst) caused by E. granulosus (EG) and AE caused by E. multilocularis (EM). Human AE is an

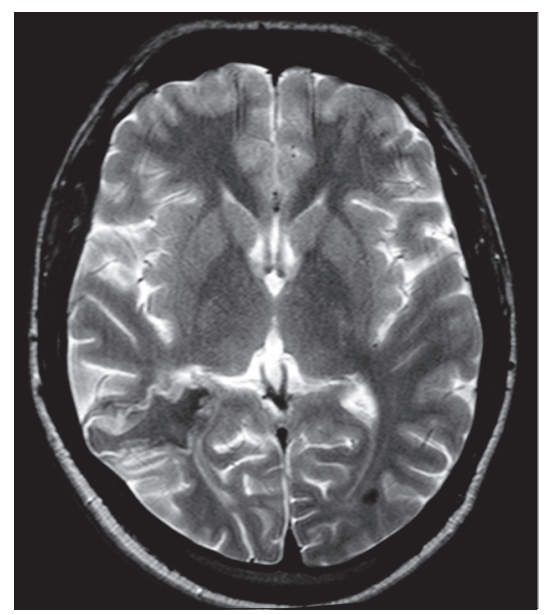

Figure 2: T2W axial MRI showing an irregular lesion in the right occipital region which is hypointense in the center with peripheral hyperintensity

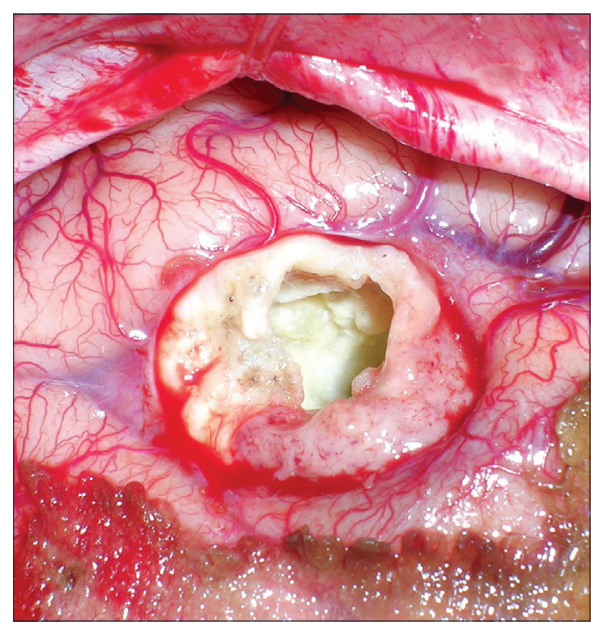

Figure 3: Intraoperative photograph showing the thickened irregular calcified wall after evacuation of contents. The plane of differentiation between the cyst wall and brain parenchyma is also visualized well

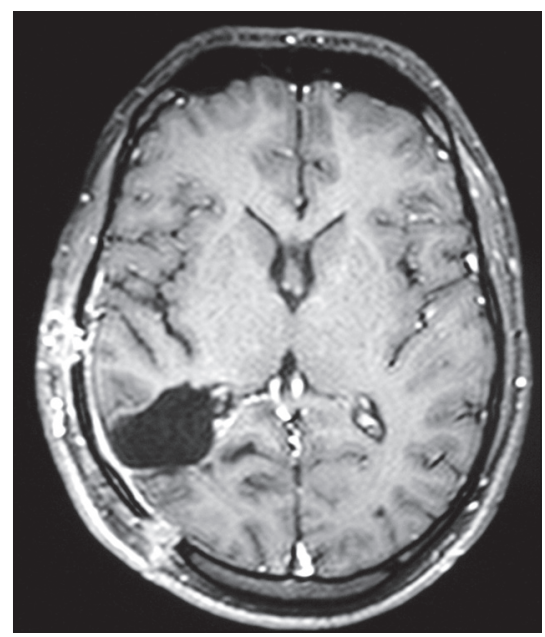

Figure 4: Postoperative contrast MRI showing total excision of lesion with postoperative changes 
uncommon zoonotic infestation caused by intrahepatic growth of the EM parasitic larvae. ${ }^{[3]}$ Cerebral metastasis is very rare, being reported in only $1 \%$ of patients. ${ }^{[7]} \mathrm{AE}$ has hitherto been unreported in the Indian subcontinent.

AE occurs in adults who live in rural areas and may appear as an infiltrative neoplasm in both the liver and brain, which makes total surgical removal difficult. ${ }^{[3,8]}$ The cyst of AE grows by external budding of the germinal membrane with progressive infiltration of the surrounding tissue ${ }^{[9]}$ Irregularly thickened and partially calcified wall is present in most cases of infestation with EM. ${ }^{[10]}$ The average age of patients with cerebral AE is significantly higher than that in cystic echinococcosis. ${ }^{[10]}$

AE on CT and MRI mainly appear as solid and semisolid or sometimes as a multilocular cystic mass. Calcification and surrounding edema are common findings of the lesions, as observed in the present case. ${ }^{[2]}$ The edema may be subtle due to chronic nature of the lesion and may not cause mass effect or midline shift. Although not always seen, contrast enhancement of the lesion has been proposed because of blood-brain barrier disruption caused by the inflammatory reaction. ${ }^{[11]}$ Peripheral ring-like, heterogenous, nodular, and cauliflower-like enhancement patterns have all been reported in different presentations of the infestation by AE. ${ }^{[3]}$

Intracranial hydatid cyst may also be classified as primary or secondary. The primary cysts are formed as a result of direct infestation of the larvae in the brain without demonstrable involvement of other organs. The primary cysts are fertile as they contain scolices and brood capsules; hence, rupture of primary cyst can result in recurrence. The secondary multiple cysts result from spontaneous, traumatic or surgical rupture of the primary intracranial hydatid cyst and they lack brood capsule and scolices. ${ }^{[4,6]}$

Patients with intracranial hydatid cysts usually present with focal neurological deficit and features of raised intracranial pressure; the latter may be due to the large size or interference with the pathway of cerebrospinal fluid (CSF) flow. ${ }^{[6]}$

Differential diagnosis includes tumors and infectious lesions such as tuberculosis and bacterial abscess. Because AE infestation simulates malignancy by its invasive nature in the brain, gliomas and metastases can also be included. ${ }^{[3]}$ Different cystic lesions like porencephalic cyst, arachnoid cyst, cystic tumor of the brain and pyogenic abscess can also mimic echinococcosis. ${ }^{[2]}$ As in our case which showed serpigenous contrast enhancement, a differential diagnosis of AVM can also be considered.

The treatment of hydatid cyst is surgical and the aim of surgery is to excise the cyst in toto without rupture to prevent recurrence or anaphylactic reaction. ${ }^{[6]}$ Various surgical options, as summarized by Arana-Iniquez, include puncture and aspiration of the cyst fluid through a small hole in the cyst wall, cortical incision over cyst and expulsion of hydatid cyst by insufflation of air in the contralateral ventricle, and the most commonly done procedure designed to give birth to the intact cyst is by irrigating saline in the cyst wall-brain interface. ${ }^{[12]}$

\section{Conclusion}

AE can be present even in the absence of distinct hepatic lesion, from a subclinical hepatic infestation even in non-endemic areas. A high index of suspicion should be maintained for hydatid cyst of brain so that adequate surgical precautions can be taken to avoid intraoperative spillage and contamination.

\section{References}

1. Andronikou S, Welman CJ, Kader E. Classic and unusual appearances of hydatid disease in children. Pediatr Radiol 2002;32:817-28.

2. Biikte Y, Kemanoglu S, Nazaroglu H, Ozkan U, Ceviz A, Simsek M. Cerebral Hydatid disease: CT and MRI findings. Swiss Med Wkly 2004;134:459-67.

3. Senturk S, Oguz KK, Soylemezoglu F, Inci S. Cerebral alveolar echinococcosis mimicking primary brain tumor. Am J Neuroradiol 2006;27:420 -22.

4. Dharker SR. Hydatid disease. In: Ramamurthi B, Tandon PN, editors. Text Book of Neurosurgery, $2^{\text {nd }}$ ed. New Delhi: Churchill Livingstone; 1996. p. 535-44.

5. Onal C, Orhan B, Metis O. Three unusual cases of intracranial hydatid cysts in paediatric age group. Pediatr Neurosurg 1997;26:208-13.

6. Gupta S, Desai K, Goel A. Intracranial hydatid cyst: A report of five cases and review of literature. Neurol India 1999;47:214-7

7. Bresson-Hadni S, Vuitton DA, Bartholomot B. Twenty-year history of alveolar echinococcosis: Analysis of a series of 117 patients from eastern France. Eur J Gastoenterol Hepatol 2000;12:327-36

8. Algros MP, Majo F, Bresson-Hadni S. Intracerebral alveolar echinococcosis. Infection 2003;31:63-5

9. Kammerer WS. Echinococcosis affecting the central nervous system. Semin Neurol 1993;13:144-7

10. Ammann RW, Eckert J. Cestodes: Echinococcus. Gastroenterol Clin North Am 1996;25:655-89.

11. Reitner P, Szolar DH, Schmid M. Systemic manifestations of echinococcus alveolaris infection. J Comput Assist Tomogr 1996;6:1030-2.

12. Iniquez RA. Echinococcus: Infection of the Nervous System. In: Vinken PJ, Bruyn GW, editors. Hand Book of Clinical Neurology, Part 3. Amsterdam: Elsevier/North Holland Biomedical Press; 1978. p. 175-208.

Source of Support: Nil, Conflict of Interest: None declared. 